\title{
Working Memory and Intelligence: A Brief Review
}

\author{
Weng-Tink Chooi ${ }^{1}$ \\ ${ }^{1}$ Advanced Medical \& Dental Institute, Universiti Sains Malaysia, Penang, Malaysia \\ Correspondence: Weng-Tink Chooi, Advanced Medical \& Dental Institute, Universiti Sains Malaysia, 13200 \\ Penang, Malaysia.Tel: 60-604-562-2304. E-mail:wengtink@amdi.usm.edu.my
}

Received: May 10, 2012

doi:10.5539/jedp.v2n2p42
Accepted: June 26, $2012 \quad$ Online Published: August 3, 2012

URL: http://dx.doi.org/10.5539/jedp.v2n2p42

\begin{abstract}
This article briefly reviews and organizes research findings from the past few decades that focused on working memory and intelligence. Working memory is a psychological construct that focuses attention, and it is commonly viewed as a temporary storage that holds and manipulates information. Intelligence is a general cognitive ability associated with efficient higher-order thinking such as reasoning and problem solving skills. Decades of research ranging from empirical to brain-behavior studies have shown a strong link between working memory and intelligence, and researchers have begun to manipulate this relationship to further study the complex psychological construct of intelligence. Although the current active research in cognitive training has created much possibility in modifying the two cognitive abilities, there is still a long way to go in achieving thorough understanding of two important constructs in human cognition.
\end{abstract}

Keywords: cognitive ability, IQ, short-term memory, processing speed, neuroscience

\section{Introduction}

Gottfredson (1997) presented convincing support that intelligence $(g)$ has a pervasive utility in everyday life, in addition to showing that higher $g$ predicted more success and better outcome in occupational attainment. It is also more advantageous to be endowed with higher $g$. People with higher $g$ (IQ above 120) were less likely to live in poverty, bear children out of wedlock, depend on social welfare and be incarcerated (for men). With such a powerful force predicting one's outcome in life, it is no wonder that many would want to study the concept and construct of $g$ to understand this powerful predicting phenomenon and hope that there is something that can be done to change or modify it to the advantage of human kind. One of the many ways researchers in social science has been utilizing to get a better grasp of $g$ is getting themselves acquainted to a mental ability that also strongly predicts academic achievement and social outcome. Cognitive psychologists have been very interested in working memory, the mental ability that actively maintains and manipulates information in the presence of interference, as a tool to understanding the nuts and bolts of intelligence, $g$.

Working memory capacity (WMC) plays an important role in predicting general intelligence (Conway, Cowan, Bunting, Therriault, \& Minkoff, 2002; Engle, Laughlin, Tuholski, \& Conway, 1999). WMC is understood as the ability to maintain active representations of information in one's mind in the presence of interference. It is conceptually defined as domain-general executive attention which manages active representations of stored domain-specific information. This conceptual definition is consistent with the working memory model proposed by A. D. Baddeley and Hitch (1974).They postulated that there are three components of the working memory model. There are two "slave systems" - the phonological loop and the visuo-spatial sketch pad - that act like short-term memory storage. The phonological loop maintains phonological information and prevents the information from decaying through rehearsal, while the visuo-spatial sketchpad stores visual and spatial information. The third component, the central executive, coordinates the information from the two slave systems by directing attention to relevant information and suppressing irrelevant information. In 2000, Baddeley added a fourth component as a third slave system, the episodic buffer, to integrate information from the other two slave systems and information from long-term memory if necessary (A. Baddeley, 2000).

The construct of intelligence, $g$ was first introduced to explain shared and common variances found in tests of mental performance. Spearman (1904)first noted that all cognitive ability tests were positively correlated with one another. He also discovered through methods of correlational analysis that the correlations among these tests could be accounted for by one factor. This factor has become known as general intelligence, or $g$. Since the conception of 
a general factor proposed to explain intelligence, there has been a persistent debate challenging the concept of $g$. Most research, however, has produced support for the existence of a higher order general factor that governs broader mental abilities manifested in mental ability tests. Carroll (2003) assembled and analyzed a variety of data sets using factor analysis, and his results indicated the "standard multifactorial view", which argued for a higher-order general intelligence influencing lower order broad mental abilities. Johnson, Bouchard Jr, Krueger, McGue, and Gottesman (2004) demonstrated that the $g$ factors from three different test batteries administered to the same sample were almost completely correlated with one another, and their findings were replicated in a study using five test batteries administered to the same group of participants (Johnson, Nijenhuis, \& Bouchard Jr, 2008). These studies strongly suggested the existence of a unitary higher-order general factor of intelligence that was not affected by how it was measured or assessed by any cognitive and mental ability tests.

The hierarchical model of human intelligence, introduced in the mid to late 1990s, has the unitary general factor, $g$, at the top stratum and group factors generally characterized by broad mental abilities on the next stratum after the general factor (Deary, 2001). The lower stratum contains specific mental abilities that contribute unique variances to the higher order broad cognitive abilities. The three-strata model of human intellectual abilities proposed by Carroll in 1993 (Carroll, 2003)and the practice of structural equation modeling in the field have provided converging support that human intelligence could be described in terms of a hierarchical structure. The VPR (verbal-perceptual-mental rotation) model proposed by Johnson and Bouchard Jr (2005b) has been subjected to constructive replication (Johnson \& Bouchard Jr, 2005a; Johnson, te Nijenhuis, \& Bouchard Jr, 2007) and offers an excellent example of the current direction and general acceptance of a hierarchical organization of human intelligence.

Although the hierarchical model of human intelligence is widely accepted in the field of intelligence, much research in and outside the field prefer to operationalize the construct $g$ with Cattell and Horn's fluid-crystallized intelligence. The fluid-crystallized intelligence model proposed by Cattell (1943) and further elaborated by Horn (1976) was the dominant theory of human intelligence since the 1970s (Johnson \& Bouchard Jr, 2005b). Fluid intelligence is characterized by general, innate abilities to solve novel problems and suggested as the ability responsible for the inter-correlations among mental ability tests or Spearman's general factor, $g$ (Cattell, 1943). Crystallized intelligence is associated with the capacity to solve problems and discriminate relations between physical or abstract elements in specialized or familiar fields. The ability to solve problems using prior accumulated knowledge is referred to as crystallized mental abilities. Although the theory proposed by Cattell and Horn did not support the unitary general factor of intelligence (Deary, 2001), the distinction between fluid and crystallized abilities inherent in Cattell and Horn's theory has played a critical role in understanding and describing individual differences in human intelligence.

The present review summarizes work done in establishing the relationship between working memory and intelligence, as well as efforts that manipulate the relationship between the two constructs in order to achieve deeper understanding of both. Works cited in this review were obtained through literature searches in the ISI Web of Knowledge and Scopus using keywords such as "working memory", "intelligence", "general cognitive/intellectual ability", "neural network" and "training". Papers focused on both WM and $g$ functions were selected. Results from the literature searches are organized in four sections below, which cover basic processes involved, empirical studies, brain-behavior studies and the modifiability of the constructs.

\section{Basic Processes Mediating the Relationship between Working Memory and Intelligence}

Based on the WM model proposed by Baddeley and Hitch, there seemed to be two basic processes that were foundation to the execution of WM processes - short-term memory storage and processing speed. The two slave systems, phonological loop and visual-spatial sketchpad, were essentially short-term storages that contained and maintained a few items at one time before losing them to decay (A. Baddeley, 2000); hence, it was possible that one's WM capacity may be influenced by the size of the slave systems. An individual who could remember more items at one time would not only perform well on STM tasks but also more likely to engage their WM better in tasks that required switching their attention back and forth, constantly updating a stream of information and mentally inhibiting irrelevant responses. Accordingly, one could assume that higher processing speed may also influence WM processes by the speed in which one coordinates the information stored in the slave systems and engaging their central executive to tend to the necessary information required for the task at hand. Researchers have suggested that the efficiency with which individuals maintained and manipulated information in their WM is the basis for reasoning ability, a skill highly associated with $g$ (Kyllonen \& Christal, 1990). Furthermore, it has been well documented that processing speed and reaction time tasks were significantly correlated with $g$ (Jensen \& Munro, 1979). 
Colom, Abad, Quiroga, Shih, and Flores-Mendoza (2008) explored the reasons behind the high correlation between WM and $g$. They conducted a study in which participants completed several reasoning ability tests, WM tasks, STM tasks, measures of mental speed and executive functioning tasks such as updating and those that could assess one's control of attention. Their confirmatory factor analyses revealed that the simple short-term storage largely accounted for the relationship between WM and $g$. The other measures were not related to WM, and they remained insignificant with their relation to $g$ after variance from the STM latent variable was removed (Colom et al., 2008).

From a developmental perspective, one could find evidence that processing speed plays a role in WM and fluid intelligence (Fry \& Hale, 1996). When age-related differences in speed, WM and fluid intelligence were statistically controlled, Fry and Hale (1996) found that individual differences in speed directly influenced WM capacity, which in turn predicted individual differences in fluid intelligence as suggested in their path analyses. They concluded that as one's processing speed increased with age, WM became more efficient and after variance from processing speed was removed from WM, it still significantly predicted fluid intelligence (Fry \& Hale, 1996).

The abovementioned studies illustrated how WM and $g$ could be related. Taken together, they suggested that the relationship is most likely caused by information storage capacity and speed in processing the stored information.

\section{Empirical Studies}

There are many studies that contributed to establishing the relationship between working memory (WM) and $g$. Kyllonen and Christal published a seminal paper in 1990 that started the excitement for the potential of the relationship between WM and $g$. The data reported in their studies suggested that reasoning ability, which was most strongly associated with $g$, could be a little more than working memory capacity (WMC). Their confirmatory factor analysis revealed a high correlation $(\mathrm{r}=0.8$ to 0.9$)$ between $\mathrm{WMC}$ and reasoning ability factors. Though a one-factor model that combined the two constructs did not fit their data as well as a two-factor model, the authors were convinced that working memory may be the driving force behind reasoning ability (Kyllonen \& Christal, 1990). Since then, there have been various publications in the literature to identify the link between WM and $g$. Ackerman, Beier, and Boyle (2005) conducted a meta-analysis of 86 such studies that related WM and $g$ and concluded that the average correlation between the two constructs was 0.48 - that they only shared about $25 \%$ common variance. Studies included in the meta-analysis reported correlation between performance on WM tasks and measures of $g$ that ranged from 0.50 to 0.90 (Colom, Flores-Mendoza, \& Rebollo, 2003; Fry \& Hale, 1996; Jurden, 1995; Salthouse, Mitchell, Skovronek, \& Babcock, 1989; Stauffer, Ree, \& Carretta, 1996; Tucker \& Warr, 1996; Verguts \& De Boeck, 2001). However, their conclusion did not reflect the bulk of contemporary view of the relationship between WM and $g$ and the data that supported the correlation. Kane, Hambrick, and Conway (2005) reanalyzed 10 latent variable studies published in the Ackerman et al. (2005) meta-analysis and suggested that WMC and reasoning abilities shared 50\% of their variance (Kane et al., 2005). Oberauer, Wilhelm, Schulze, and Süß (2005) also reanalyzed the studies that employed structural equation modeling published in Ackerman et al. (2005) meta-analysis, and they suggested an even stronger correlation between the two constructs $(r=0.85)$. The compilation of the latent-variable analysis seemed to indicate that WM and $g$ shared between $50-70 \%$ common variance (Kane et al., 2005; Oberauer et al., 2005).

Besides the strong correlation between WM and g, numerous studies such as latent variable analyses also indicatedWMas a good predictor of $g$. Results from these analyses provided support and explanation to the high correlations between working memory and general intelligence established in the literature (Ackerman et al., 2005; Conway, Kane, \& Engle, 2003). Engle et al. (1999) andConway et al. (2002) suggested that short term memory (STM) is a subset of WMC as supported by the definition of WMC, which included both executive functions and the storage of information. In their analyses, after they had removed the shared variance between STM and WMC, the remaining variance in WMC was still a significant predictor of general intelligence, $g$. Engle et al. (1999) reported a correlation of $0.49(\mathrm{p}<0.05)$ between $g$ and the unique variance of WMC independent of STM. The significant correlation between variances from WMC and $g$ in simple correlational studies and latent variable analyses provided strong support that the two constructs were related through sharing a common underlying ability that manifested itself in measures of WMC and $g$.

\section{Brain-behavior Studies}

An example of studies in cognitive psychology and neuroscience that tried to explain the relationship between WM and intelligence is one by Halford, Cowan, and Andrews (2007). The authors suggested that WM and reasoning ability shared related capacity limits, and the two functions were related through the shared requirement that binds elements to slots of a hypothetical coordinate system in one's memory. The process of maintaining the 
bindings between elements required attention that was essential to WM and reasoning abilities. The authors believed that "the common demand for attention when binding elements into slots is a possible explanation for common capacity limitations in WM and reasoning" (p. 236). These limits are most likely based on a restrained capability to form and preserve bindings of elements in memory. Research in the field of neuroscience also suggested that attention is a function of the prefrontal cortex, and that the relation between fluid intelligence $\left(g_{f}\right)$ and WM was mediated by activities in the lateral prefrontal and parietal regions (Gray et al., 2003). Kane and Engle (2002) reported that the dorsolateral prefrontal cortex could have a role in WM especially related to attention control. Conway et al. (2003) supported the hypothesis by Gray et al. (2003) that WM span tasks activate regions in the prefrontal cortex when the executive-control mechanism is engaged in combating interference during the maintenance and manipulation of information. Jung and Haier (2007) reviewed 37 neuroimaging studies on the location of $g$ in the brain. The product of their extensive review was that $g$ is most likely distributed across several regions in the brain - specifically, the areas most relevant to intelligent behavior may be concentrated in the parietal and frontal lobes of the brain. This led Jung and Haier (2007) to propose the Parietal-Frontal Integration Theory (P-FIT), which suggested that $g$ is not specific to any area but an integration of several regions in the brain. These areas were also commonly associated with WM, control of attention, planning, reasoning, decision making, memory retrieval and executive functioning (Colom et al., 2009). The postulated shared neural network between $g$ and WM provided further support that they may share something fundamental to higher order cognition (Jaeggi, Buschkuehl, Jonides, \& Perrig, 2008).

Changes in neural activity after practice on WM tasks added support to the P-FIT model (Jung \& Haier, 2007) and the common neural network between WM and $g$ (Conway et al., 2003; Kane \& Engle, 2002) when Jolles, Grol, Van Buchem, Rombouts, and Crone (2010) detected changes in the left ventrolateral prefrontal cortex, bilateral dorsolateral prefrontal cortex and left superior parietal cortex. Increased activation was observed in the striatum area during manipulation trials in WM tasks (Dahlin, Neely, Larsson, Bäckman, \& Nyberg, 2008; Jolles et al., 2010). The brain-behavior studies that explored the relationship between WM and $g$ seemed to advocate that WM is an important sub-component of general cognitive ability when viewed from a biological point of view, and this principle further strengthened the relationship between WM and $g$.

\section{Modifiability of WM and/or $g$}

There are cumulating interest and research in cognitive training, especially WM training (Morrison \& Chein, 2011). Numerous studies have reported training and transfer effects as a result of WM, executive function, and attention type training, most of which were done in young children or the older adult population. Klingberg and colleagues $(2005 ; 2002)$ observed improvements in matrix reasoning tasks in addition to reduced inattentive symptoms in children with Attention Deficit Hyperactivity Disorder (ADHD). Others found improvements in fluid reasoning after training on WM in older adults(Borella, Carretti, Riboldi, \& De Beni, 2010; Schmiedek, Lovden, \& Lindenberger, 2010).WM training studies done on old adults (Buschkuehl et al., 2008) impacted memory performance, a near transfer effect, and these studies did not report significant improvements on $g_{f}$ tasks. Van der Molen and colleagues (2010) found short-term memory improvement and did not find IQ score improvements in adolescents with mild intellectual disability. Li and colleagues(2008) reported no far transfer effects from WM training to complex span tasks and did not report improvements in measures of IQ.

There were plenty of studies that found near transfer after WM training but not so much on far transfer effects. Near transfer referred to changes in a domain affected by changes in another domain due to comparable ability or process, and far transfer effects referred to changes in domains caused by activities in a separate domain of different processes. Many WM training studies were conducted on children ranging from 4 to 11 years of age, when their cognitive abilities were still developing and have not reached maturity (Fry \& Hale, 2000). Bergman Nutley et al. (2011) reported consistent near transfer effects in their study on 4-year old children. The authors observed improvements on reasoning tasks in children that trained on reasoning skills, and they failed to find transfer effects from WM training to reasoning and fluid intelligence tasks. More examples of near transfer effect included a study by Mackey et al. (2011), St. Clair-Thompson et al. (2010) and Thorell et al. (2009) that reported near transfer effects but neither far transfer effects nor improvements in IQ measures. Holmes et al. (2010)reported that IQ scores were unaffected by WM training in children with ADHD, andHolmes, Gathercole, and Dunning (2009) reported no boost in IQ performance in children with low working memory capacity. A recent review by Diamond and Lee (2011) on cognitive training conducted on children concluded that only core executive function - WM, cognitive flexibility and inhibition - training is most beneficial to 4-12 year-olds, and most studies cited in this review reported near transfer effects.

Colom et al. (2010) further explored the hypothesis of transfer effects from improved performance on WM tasks to measures of $g$ by comparing performance of students in two groups. One group worked on STM and WM 
tasks that were highly demanding for three weeks, and the other worked on processing speed and attention tasks which were less cognitively demanding than the first group. Both groups worked on their tasks for three weeks, once every week, between pre-test and post-test sessions. Scores from both groups at post-test session increased significantly from their pre-test scores. Even so, factor analysis showed that there were no significant changes in the most $g$-loaded tests (Colom et al., 2010). Based on their results, Colom and his colleagues (2010) strongly suggested that cognitive abilities such as general intelligence, WM, STM, processing speed and attention have a high degree of stability.

So far, transfer effects were mostly found in studies that were conducted on children and older adults, when their cognitive functions during stages of development or decline were relatively malleable than young adults (Borella et al., 2010; Fry \& Hale, 2000). Modifying cognitive abilities did not seem to be difficult during periods of growth when interventions could assist and perhaps accelerate development and maturity (Rueda, Rothbart, McCandliss, Saccomanno, \& Posner, 2005). Modification was also promising in old adults when their cognitive decline could be delayed with intervention (Basak, Boot, Voss, \& Kramer, 2008; Borella et al., 2010; Buschkuehl et al., 2008). Consistent with the "disuse" hypothesis (Orrell \& Sahakian, 1995), the potential of slowing down cognitive decline is supported by animal and human studies that demonstrated considerable neuronal plasticity due to increased activities from experiential input and perceptual-sensory stimuli (Tranter \& Koutstaal, 2008). However, studies that suggested possible alteration of cognitive abilities in young adults, when general cognitive abilities are less pliable compared to childhood and aging periods, are considerably fewer (Jaeggi et al., 2008; Jaeggi et al., 2010; Schmiedek et al., 2010). The stability of general cognitive abilities in adulthood raised questions as to how effective and how long changes as a result from cognitive training could last in terms of cognitive functions and behavior. There should be more studies conducted on healthy, young adults before researchers could claim with confidence that general cognitive abilities such as fluid reasoning could be improved with short periods of cognitive training.

\section{Conclusion}

The bulk of data from the literature captured in the present review strongly suggested that working memory and intelligence were neither isomorphic nor identical constructs (Ackerman et al., 2005; Kane et al., 2005; Oberauer et al., 2005), although it was quite clear that both of these constructs were highly related to one another (Colom et al., 2003; Kyllonen \& Christal, 1990). The high correlation was postulated to be based on shared fundamental neural mechanisms in the dorsolateral prefrontal regions in the brain (Conway et al., 2003; Kane \& Engle, 2002; Klingberg, 2010) and basic mental processes such as short-term memory storage (Colom et al., 2008) and processing speed (Fry \& Hale, 1996). The recent attempts to raise intelligence through improving WM processes (Morrison \& Chein, 2011) have created much controversy in the field of cognitive psychology. Although results seemed to be encouraging and positive, more research needed to be done to replicate and explain the generally inconclusive results obtained from these early efforts especially when there are currently more studies that reported near transfer effects compared to far transfer effects. Efforts to improve general cognitive ability such as $g$ has a long history of minimal success (Spitz \& Johnstone, 1986) and transfer from a learned task to a novel task has not been shown to occur (Detterman \& Sternberg, 1993). The notion of improving $g$ through WM training should be further scrutinized as the evidence provided thus far is weak. Additionally, a major limitation in current research involved measuring improvements in $g$ with only one single task. The latent ability should be targeted and measured with several tasks of $g$ to study whether effects of WM training could generalize to other cognitive abilities (Shipstead, Redick, \& Engle, 2012).

Nevertheless, the literature on WM and $g$ has shown to be an exciting and challenging area in which researchers attempt to identify, explain and relate specific mental abilities to one another. We currently have an idea on how and why WM might relate to $g$, but there is much more to be done in explaining the relationship. The current progress of research in this area gives great hope that we may better understand general intelligence, a powerful predictor of life outcome, through the framework of the complex, higher order cognitive skill of WM.

\section{References}

Ackerman, P. L., Beier, M. E., \& Boyle, M. O. (2005). Working memory and intelligence: The same or different constructs? Psychological Bulletin, 131(1), 30-60. http://dx.doi.org/10.1037/0033-2909.131.1.30

Baddeley, A. (2000). The episodic buffer: a new component of working memory? Trends in Cognitive Sciences, 4(11), 417-423. http://dx.doi.org/10.1016/S1364-6613(00)01538-2

Baddeley, A. D., \& Hitch, G. J. (1974). Working Memory. In G. H. Bower (Ed.), The psychology of learning and motivation: Advances in research and theory (Vol. 8, pp. 47-89). New York: Academic Press. 
Basak, C., Boot, W. R., Voss, M. W., \& Kramer, A. F. (2008). Can Training in a Real-Time Strategy Video Game Attenuate Cognitive Decline in Older Adults? Psychology and Aging, 23(4), 765-777. http://dx.doi.org/10.1037/a0013494

Bergman Nutley, S., Söderqvist, S., Bryde, S., Thorell, L. B., Humphreys, K., \& Klingberg, T. (2011). Gains in fluid intelligence after training non-verbal reasoning in 4-year-old children: A controlled, randomized study. Developmental Science, 14(3), 591-601. http://dx.doi.org/10.1111/j.1467-7687.2010.01022.x

Borella, E., Carretti, B., Riboldi, F., \& De Beni, R. (2010). Working Memory Training in Older Adults: Evidence of Transfer and Maintenance Effects. Psychology and Aging, 25(4), 767-778. http://dx.doi.org/10.1037/a0020683

Buschkuehl, M., Jaeggi, S. M., Hutchison, S., Perrig-Chiello, P., Däpp, C., Müller, M., . . Perrig, W. J. (2008). Impact of Working Memory Training on Memory Performance in Old-Old Adults. Psychology and Aging, 23(4), 743-753. http://dx.doi.org/10.1037/a0014342

Carroll, J. B. (2003). The higher-stratum structure of cognitive abilities: Current evidence supports $g$ and 10 broad factor. In H. Nyborg (Ed.), The scientific study of general intelligence: Tribute to Arthur R. Jensen (pp. 5-21). Amsterdam: Pergamon.

Cattell, R. B. (1943). The measurement of adult intelligence. Psychological Bulletin, 40(3), 153-193. http://dx.doi.org/10.1037/h0059973

Colom, R., Abad, F. J., Quiroga, M. Á., Shih, P. C., \& Flores-Mendoza, C. (2008). Working memory and intelligence are highly related constructs, but why? Intelligence, 36(6), 584-606. http://dx.doi.org/10.1016/j.intell.2008.01.002

Colom, R., Flores-Mendoza, C., \& Rebollo, I. (2003). Working memory and intelligence. Personality and Individual Differences, 34(1), 33-39. http://dx.doi.org/10.1016/S0191-8869(02)00023-5

Colom, R., Haier, R. J., Head, K., Álvarez-Linera, J., Quiroga, M. Á., Shih, P. C., \& Jung, R. E. (2009). Gray matter correlates of fluid, crystallized, and spatial intelligence: Testing the P-FIT model. Intelligence, 37(2), 124-135. http://dx.doi.org/10.1016/j.intell.2008.07.007

Colom, R., Quiroga, M. Á., Shih, P. C., Martínez, K., Burgaleta, M., Martínez-Molina, A., . . Ramírez, I. (2010). Improvement in working memory is not related to increased intelligence scores. Intelligence, 38(5), 497-505. http://dx.doi.org/10.1016/j.intell.2010.06.008

Conway, A. R. A., Cowan, N., Bunting, M. F., Therriault, D. J., \& Minkoff, S. R. B. (2002). A latent variable analysis of working memory capacity, short-term memory capacity, processing speed, and general fluid intelligence. Intelligence, 30(2), 163-183. http://dx.doi.org/10.1016/S0160-2896(01)00096-4

Conway, A. R. A., Kane, M. J., \& Engle, R. W. (2003). Working memory capacity and its relation to general intelligence. Trends in Cognitive Sciences, 7(12), 547-552. http://dx.doi.org/10.1016/j.tics.2003.10.005

Dahlin, E., Neely, A. S., Larsson, A., Bäckman, L., \& Nyberg, L. (2008). Transfer of learning after updating

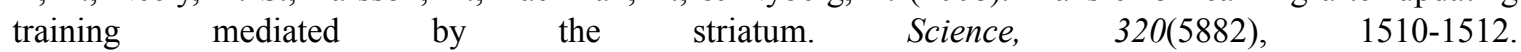
http://dx.doi.org/10.1126/science.1155466

Deary, I. J. (2001). Human intelligence differences: A recent history. Trends in Cognitive Sciences, 5(3), 127-130. http://dx.doi.org/10.1016/S1364-6613(00)01621-1

Detterman, D. K., \& Sternberg, R. J. (1993). Transfer on trial: Intelligence, cognition and instruction. Norwood, NJ: Ablex Publishing.

Diamond, A., \& Lee, K. (2011). Interventions shown to aid executive function development in children 4 to 12 years old. Science, 333(6045), 959-964. http://dx.doi.org/10.1126/science.1204529

Engle, R. W., Laughlin, J. E., Tuholski, S. W., \& Conway, A. R. A. (1999). Working memory, short-term memory, and general fluid intelligence: A latent-variable approach. Journal of Experimental Psychology: General, 128(3), 309-331. http://dx.doi.org/10.1037/0096-3445.128.3.309

Fry, A. F., \& Hale, S. (1996). Processing Speed, Working Memory, and Fluid Intelligence: Evidence for a $\begin{array}{lllll}\text { Developmental } & \text { Cascade. } & \text { Psychological } & \text { Science, } & 7(4),\end{array}$ http://dx.doi.org/10.1111/j.1467-9280.1996.tb00366.x

Fry, A. F., \& Hale, S. (2000). Relationships among processing speed, working memory, and fluid intelligence in children. Biological Psychology, 54(1-3), 1-34. http://dx.doi.org/10.1016/S0301-0511(00)00051-X 
Gottfredson, L. S. (1997). Why g matters: The complexity of everyday life. Intelligence, 24(1), 79-132. http://dx.doi.org/10.1016/S0160-2896(97)90014-3

Gray, J. R., Chabris, C. F., \& Braver, T. S. (2003). Neural mechanisms of general fluid intelligence. Nature Neuroscience, 6(3), 316-322. http://dx.doi.org/10.1038/nn1014

Halford, G. S., Cowan, N., \& Andrews, G. (2007). Separating cognitive capacity from knowledge: a new hypothesis. Trends in Cognitive Sciences, 11(6), 236-242. http://dx.doi.org/10.1016/j.tics.2007.04.001

Holmes, J., Gathercole, S. E., \& Dunning, D. L. (2009). Adaptive training leads to sustained enhancement of poor working memory in children. Developmental Science, 12(4), F9-F15. http://dx.doi.org/10.1111/j.1467-7687.2009.00848.x

Holmes, J., Gathercole, S. E., Place, M., Dunning, D. L., Hilton, K. A., \& Elliott, J. G. (2010). Working memory deficits can be overcome: Impacts of training and medication on working memory in children with ADHD. Applied Cognitive Psychology, 24(6), 827-836. http://dx.doi.org/10.1002/acp.1589

Horn, J. L. (1976). Human abilities: a review of research and theory in the early 1970s. Annual Review of Psychology, 27, 437-485. http://dx.doi.org/10.1146/annurev.ps.27.020176.002253

Jaeggi, S. M., Buschkuehl, M., Jonides, J., \& Perrig, W. (2008). Improving fluid intelligence with training on working memory. Proceedings of the National Academy of Sciences of the United States of America.

Jaeggi, S. M., Studer-Luethi, B., Buschkuehl, M., Su, Y.-F., Jonides, J., \& Perrig, W. (2010). The relationship between n-back performance and matrix reasoning - implications for training and transfer. Intelligence, 38, 625-635. http://dx.doi.org/10.1016/j.intell.2010.09.001

Jensen, A. R., \& Munro, E. (1979). Reaction time, movement time, and intelligence. Intelligence, 3(2), 121-126.

Johnson, W., \& Bouchard Jr, T. J. (2005a). Constructive replication of the visual - Perceptual-image rotation model in Thurstone's (1941) battery of 60 tests of mental ability. Intelligence, 33(4), 417-430.

Johnson, W., \& Bouchard Jr, T. J. (2005b). The structure of human intelligence: It is verbal, perceptual, and image rotation (VPR), not fluid and crystallized. Intelligence, 33(4), 393-416. http://dx.doi.org/10.1016/j.intell.2004.12.002

Johnson, W., Bouchard Jr, T. J., Krueger, R. F., McGue, M., \& Gottesman, I. I. (2004). Just one g: Consistent $\begin{array}{lllll}\text { results from three test } & \text { batteries. }\end{array}$ http://dx.doi.org/10.1016/S0160-2896(03)00062-X

Johnson, W., Nijenhuis, J. T., \& Bouchard Jr, T. J. (2008). Still just $1 \mathrm{~g}$ : Consistent results from five test batteries. Intelligence, 36(1), 81-95. http://dx.doi.org/10.1016/j.intell.2007.06.001

Johnson, W., te Nijenhuis, J., \& Bouchard Jr, T. J. (2007). Replication of the hierarchical visual-perceptual-image rotation model in de Wolff and Buiten's (1963) battery of 46 tests of mental ability. Intelligence, 35(1), 69-81. http://dx.doi.org/10.1016/j.intell.2006.05.002

Jolles, D. D., Grol, M. J., Van Buchem, M. A., Rombouts, S. A. R. B., \& Crone, E. A. (2010). Practice effects in the brain: Changes in cerebral activation after working memory practice depend on task demands. NeuroImage, 52(2), 658-668. http://dx.doi.org/10.1016/j.neuroimage.2010.04.028

Jung, R. E., \& Haier, R. J. (2007). The Parieto-Frontal Integration Theory (P-FIT) of intelligence: Converging neuroimaging evidence. Behavioral and Brain Sciences, 30(2), 135-154. http://dx.doi.org/10.1017/S0140525X07001185

Jurden, F. H. (1995). Individual Differences in Working Memory and Complex Cognition. Journal of Educational Psychology, 87(1), 93-102. http://dx.doi.org/10.1037/0022-0663.87.1.93

Kane, M. J., \& Engle, R. W. (2002). The role of prefrontal cortex in working-memory capacity, executive attention, and general fluid intelligence: An individual-differences perspective. Psychonomic Bulletin and Review, 9(4), 637-671. http://dx.doi.org/10.3758/BF03196323

Kane, M. J., Hambrick, D. Z., \& Conway, A. R. A. (2005). Working memory capacity and fluid intelligence are strongly related constructs: Comment on Ackerman, Beier, and Boyle. Psychological Bulletin, 131(1), 66-71. http://dx.doi.org/10.1037/0033-2909.131.1.66

Klingberg, T. (2010). Training and plasticity of working memory. Trends in Cognitive Sciences, 14(7), 317-324. http://dx.doi.org/10.1016/j.tics.2010.05.002

Klingberg, T., Fernell, E., Olesen, P. J., Johnson, M., Gustafsson, P., Dahlström, K., . . Westerberg, H. (2005). 
Computerized training of working memory in children with ADHD - A randomized, controlled trial. Journal of the American Academy of Child and Adolescent Psychiatry, 44(2), 177-186. http://dx.doi.org/10.1097/00004583-200502000-00010

Klingberg, T., Forssberg, H., \& Westerberg, H. (2002). Training of working memory in children with ADHD. Journal of Clinical and Experimental Neuropsychology, 24(6), 781-791. http://dx.doi.org/10.1076/jcen.24.6.781.8395

Kyllonen, P. C., \& Christal, R. E. (1990). Reasoning ability is (little more than) working-memory capacity?! Intelligence, 14(4), 389-433. http://dx.doi.org/10.1016/S0160-2896(05)80012-1

Li, S. C., Schmiedek, F., Huxhold, O., Röcke, C., Smith, J., \& Lindenberger, U. (2008). Working Memory Plasticity in Old Age: Practice Gain, Transfer, and Maintenance. Psychology and Aging, 23(4), 731-742. http://dx.doi.org/10.1037/a0014343

Mackey, A. P., Hill, S. S., Stone, S. I., \& Bunge, S. A. (2011). Differential effects of reasoning and speed training in children. Developmental Science, 14(3), 582-590. http://dx.doi.org/10.1111/j.1467-7687.2010.01005.x

Morrison, A. B., \& Chein, J. M. (2011). Does working memory training work? the promise and challenges of enhancing cognition by training working memory. Psychonomic Bulletin and Review, 18(1), 46-60. http://dx.doi.org/10.3758/s13423-010-0034-0

Oberauer, K., Wilhelm, O., Schulze, R., \& Süß, H. M. (2005). Working memory and intelligence -Their correlation and their relation: Comment on Ackerman, Beier, and Boyle. Psychological Bulletin, 131(1), 61-65. http://dx.doi.org/10.1037/0033-2909.131.1.61

Orrell, M., \& Sahakian, B. (1995). Education and dementia. British Medical Journal, 310(6985), 951-952. http://dx.doi.org/10.1136/bmj.310.6985.951

Rueda, M. R., Rothbart, M. K., McCandliss, B. D., Saccomanno, L., \& Posner, M. I. (2005). Training, maturation, and genetic influences on the development of executive attention. Proceedings of the National Academy of Sciences of the United States of America, 102(41), 14931-14936. http://dx.doi.org/10.1073/pnas.0506897102

Salthouse, T. A., Mitchell, D. R. D., Skovronek, E., \& Babcock, R. L. (1989). Effects of Adult Age and Working Memory on Reasoning and Spatial Abilities. Journal of Experimental Psychology: Learning, Memory, and Cognition, 15(3), 507-516. http://dx.doi.org/10.1037/0278-7393.15.3.507

Schmiedek, F., Lovden, M., \& Lindenberger, U. (2010). Hundred days of cognitive training enhance broad cognitive abilities in adulthood: findings from the COGITO study. Frontiers in Aging Neuroscience, 2.

Shipstead, Z., Redick, T. S., \& Engle, R. W. (2012). Is Working Memory Training Effective? Psychol Bull. http://dx.doi.org/10.1037/a0027473

Spearman, C. (1904). General Intelligence, objectively determined and measured. American Journal of Psychology, 15(2), 201-292. http://dx.doi.org/10.2307/1412107

Spitz, H. H., \& Johnstone, E. R. (1986). The Raising of Intelligence: A Selected History of Attempts to Raise Retarded Intelligence. Hillsdale, NJ: Lawrence Erlbaum Associates.

St Clair-Thompson, H., Stevens, R., Hunt, A., \& Bolder, E. (2010). Improving children's working memory and $\begin{array}{llll}\text { classroom } & \text { performance. } & \text { Educational } & \text { Psychology, }\end{array}$ http://dx.doi.org/10.1080/01443410903509259

Stauffer, J. M., Ree, M. J., \& Carretta, T. R. (1996). Cognitive-Components Tests Are Not Much More Than g: An Extension of Kyllonen's Analyses. Journal of General Psychology, 123(3), 193-205. http://dx.doi.org/10.1080/00221309.1996.9921272

Thorell, L. B., Lindqvist, S., Nutley, S. B., Bohlin, G., \& Klingberg, T. (2009). Training and transfer effects of executive functions in preschool children. Developmental Science, 12(1), 106-113. http://dx.doi.org/10.1111/j.1467-7687.2008.00745.x

Tranter, L. J., \& Koutstaal, W. (2008). Age and flexible thinking: An experimental demonstration of the beneficial effects of increased cognitively stimulating activity on fluid intelligence in healthy older adults. Aging, Neuropsychology, and Cognition, 15(2), 184-207. http://dx.doi.org/10.1080/13825580701322163

Tucker, P., \& Warr, P. (1996). Intelligence, elementary cognitive components, and cognitive styles as predictors of complex task performance. Personality and Individual Differences, 21(1), 91-102. 
http://dx.doi.org/10.1016/0191-8869(96)00032-3

Van der Molen, M. J., Van Luit, J. E. H., Van der Molen, M. W., Klugkist, I., \& Jongmans, M. J. (2010). Effectiveness of a computerised working memory training in adolescents with mild to borderline intellectual disabilities. Journal of Intellectual Disability Research, 54(5), 433-447. http://dx.doi.org/10.1111/j.1365-2788.2010.01285.x

Verguts, T., \& De Boeck, P. (2001). On the correlation between working memory capacity and performance on intelligence tests. Learning and Individual Differences, $13(1), \quad 37-55$. http://dx.doi.org/10.1016/S1041-6080(02)00049-3 